\begin{tabular}{|cc|}
\hline HYDROLYSIS & DIGESTION \\
METHANE & CARBON DIOXIDE \\
LIMONENE & $p$-CYMENE \\
ANALYSIS & GSC - GLC - MS \\
\hline
\end{tabular}

Open access revised manuscript version of

Environmental Technology 19 (1998) 639-642

Link to publisher

\title{
Hydrocarbons in biogas from household solid waste
}

\author{
Susan Björkqvist, Morgan Fröling, \\ Hanna Härelind-Ingelsten and Göran Petersson
}

Alternative treatments of household waste were compared in a subsequent study (in Swedish):

Biobränsle från hushållsavfall 


\title{
HYDROCARBONS IN BIOGAS FROM HOUSEHOLD SOLID WASTE
}

\author{
Susan BJörkqvist, Morgan Frōling, Hanna Härelind-Ingelsten and Göran Petersson. \\ Department of Chemical Environmental Science, \\ Chalmers University of Technology, 41296 Göteborg, Sweden.
}

\begin{abstract}
The components of biogas from source-separated domestic waste were studied for the first major Swedish plant (Sobacken, Borås) in operation. Methane, carbon dioxide and $\mathrm{C}_{6}-\mathrm{C}_{11}$ hydrocarbons were determined by gas chromatographic methods. The content of methane was found to be just over $70 \%(\mathrm{v} / \mathrm{v})$. The major polluting hydrocarbon in the biogas was $p$-cymene. It may be formed by rearrangement and dehydrogenation of limonene and other monoterpenes in food waste.
\end{abstract}

Keywords: Anaerobic digestion, food waste, methane, $p$-cymene, limonene.

\section{INTRODUCTION}

Biological treatment of household solid waste is presently an issue of great interest in many countries $[1,2]$ due to the need to develop environmentally sustainable methods for municipal solid waste handling. Anaerobic digestion with biogas production appears to be an attractive option. It is a rapidly developing technology with a large number of recently started plants, especially in Europe.

With respect to both process chemistry and biogas use, knowledge of the biogas composition is of importance. The purpose of this study was to apply suitable analytical methods to the determination of both major and trace components of biogas from a Swedish plant operated specifically for household solid waste. 


\section{MATERIALS AND METHODS}

\section{Household waste and biogas production}

The Sobacken waste treatment plant in Borås in western Sweden started operation in 1995 and receives about 8,000 tonnes yearly of source-separated organic solid waste from 50,000 households. After grinding and removal of the coarse fraction by a drum sieve, about 4,000 tonnes of the waste remain to be treated as shown in Figure 1 for production of $80-100 \mathrm{~m}^{3}$ of biogas per tonne of waste. The biogas is produced in a two-step anaerobic digestion system [3] with recirculation of the process water. In the first step, the organic solid waste is dissolved into water. Hydrolysis and fermentation take place for 2-3 days. The undigested solid phase is then separated and treated by composting. In the second step, the water phase is fed into a packed column reactor where methane formation takes place over a period of 1-2 days. The process water is aerated and fed back into the hydrolysis step. Each step is optimized physically and chemically to obtain the best conditions for gas production. With the two-stage system, the dwell time is considerably reduced compared with conventional single-stage digestion systems with the same methane yield [4]. In addition, the low $\mathrm{pH}$ in the hydrolysis step keeps metals in the ionic form permitting them to be partially removed from the solid phase and thereby from the compost product.

\section{Analytical methods}

Biogas samples were taken in 0.51 cylindrical glass vessels with valves at both ends.

Methane and carbon dioxide: Separation and quantitative determination of $\mathrm{CH}_{4}, \mathrm{CO}_{2}$, $\mathrm{N}_{2}$ and $\mathrm{O}_{2}$ were performed using a gas chromatograph (Perkin-Elmer 3920B) with gas injection valves, two different columns, and a hot-wire detector $\left(200^{\circ} \mathrm{C}, 150 \mathrm{~mA}\right)$. Methane, $\mathrm{N}_{2}$ and $\mathrm{O}_{2}$ were analysed on a column $(170 \mathrm{~cm} \times 1 / 8$ " o.d.) packed with the molecular sieve $13 \mathrm{X}$ as the stationary phase. Carbon dioxide was subsequently determined using a column (190 $\mathrm{cm} \mathrm{x} \mathrm{1/8"} \mathrm{o.d.)} \mathrm{with} \mathrm{the}$ porous polymer HayeSep Q (60-80 mesh) as the stationary phase. The separations were performed 


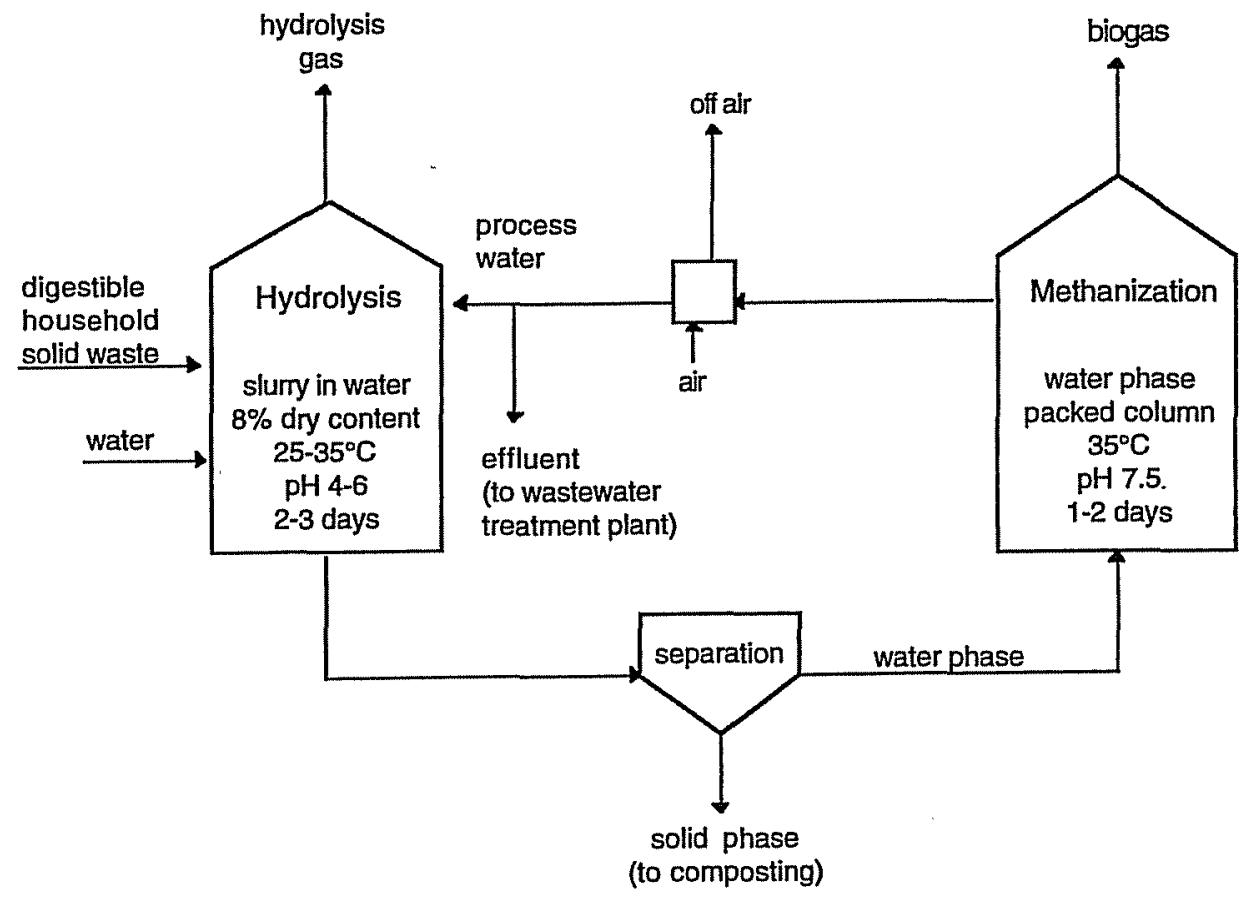

Figure 1 Schematic representation of the two-step process for biogas production in Borås, Sweden.
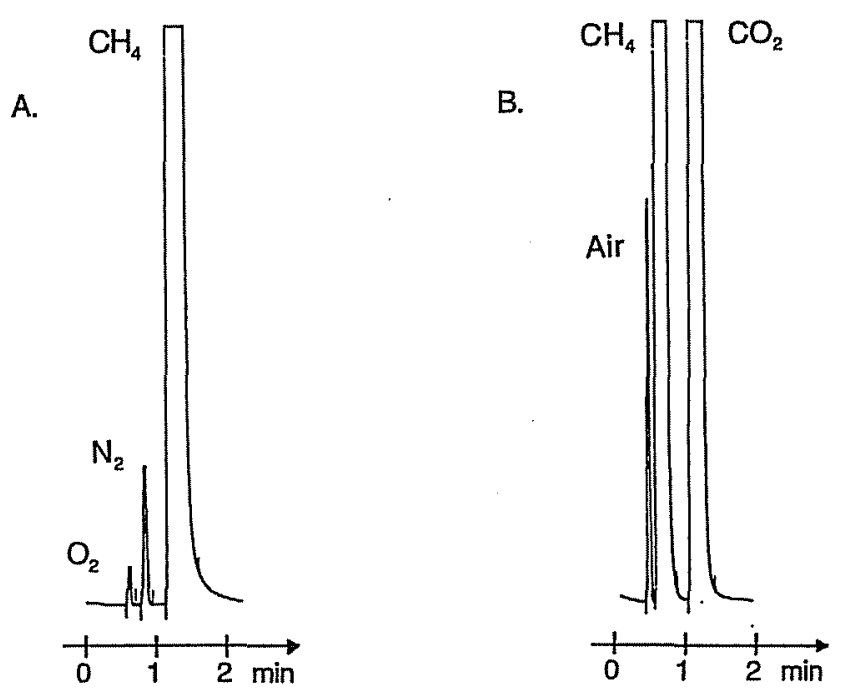

Figure 2 Dual-column gas chromatographic assessment of methane and carbon dioxide in biogas (A: Molecular sieve 13X; B: Porous polymer HayeSep Q) 
isothermally at $80^{\circ} \mathrm{C}$ with helium $\left(25 \mathrm{ml} \mathrm{min}^{-1}\right)$ as the carrier gas. The injected biogas volumes were $290 \mu \mathrm{l}(13 \mathrm{X}$ column) and $190 \mu \mathrm{l}$ (HayeSep Q column).

Non-methane hydrocarbons: Using constant-flow air pumps, accurately determined biogas volumes $(20 \mathrm{ml})$ from the biogas sampling vessel were passed $\left(5 \mathrm{ml} \mathrm{min}^{-1}\right)$ through glass cartridges (15 cm x $3 \mathrm{~mm}$ i.d.) filled with an adsorbent (Tenax TA, 60-80 mesh). The cartridge was placed in the injector of a gas chromatograph (Varian 3300) for thermal desorption $\left(230^{\circ} \mathrm{C}, 10 \mathrm{~min}\right.$, $\mathrm{He}$ ) onto the analytical fused silica open tubular column ( $50 \mathrm{~m} \times 0.32 \mathrm{~mm}$ i.d.). The stationary phase was a cross-linked methylsilicone (DB-1, $1 \mu \mathrm{m}$ phase layer). The column temperature, kept at $-50^{\circ} \mathrm{C}$ during thermal desorption, was raised rapidly to room temperature and was then increased linearly $\left(2.5^{\circ} \mathrm{C} \mathrm{min}^{-1}\right)$ to the final temperature $\left(200^{\circ} \mathrm{C}\right)$. The carrier gas was helium $\left(25 \mathrm{~cm} \mathrm{~s}^{-1}\right)$ and detection was by flame ionisation. Trace amounts of artifact hydrocarbons from laboratory ambient air and from the adsorbent during thermal desorption were negligible compared with the amounts determined from the gas samples.

Samples of air inside the drum sieve and of hydrolysis gas were taken similarly, either directly on Tenax cartridges at the biogas plant, or indirectly after initial glass vessel sampling. The cartridge sampling volumes were in the range $20-100 \mathrm{ml}$.

Mass spectrometric identifications were made using a Varian Saturn 2000 ion trap $\left(100^{\circ} \mathrm{C}\right) \mathrm{GC}-\mathrm{MS}$ instrument. The analytical methylsilicone column and the temperature program were similar to those described above, resulting in similar chromatograms. Biogas was injected using a gas syringe $(500 \mu \mathrm{l})$ and the carrier gas $\left(30 \mathrm{~cm} \mathrm{~s}^{-1}\right)$ was helium. Mass spectra $(\mathrm{m} / z$ 35-200) were scanned automatically every second. The identifications were based on spectra interpretations and on comparisons with NIST library spectra. 


\section{RESULTS AND DISCUSSION}

\section{Major biogas components}

The gas chromatograms in Figure 2 illustrate the rapid analytical determination of biogas components. The results given in Table 1 are indicative of both the biogas composition and the quality of the analytical methods applied. Partial condensation in the sampling vessel of the water content (1-2\%) in the biogas may explain the somewhat varying $\mathrm{CH}_{4}$ and $\mathrm{CO}_{2}$ percentages. Low proportions of $\mathrm{N}_{2}$ and $\mathrm{O}_{2}$ confirm that air was satisfactorily excluded both in the biogas process and during sampling and analysis.

Table 1. Composition of biogas produced from household solid waste in Borås. Averages (\% v/v) with standard deviations for four to six GC determinations of biogas in each of three sampling vessels (A, B and C), 26 November 1996.

\begin{tabular}{lllll}
\hline Vessel & $\mathrm{CH}_{4}$ & $\mathrm{CO}_{2}$ & $\mathrm{~N}_{2}$ & $\mathrm{O}_{2}$ \\
\hline $\mathrm{A}(\mathrm{n}=6)$ & $70.4 \pm 0.6$ & $27.2 \pm 0.3$ & $<1.0$ & $<0.5$ \\
& & & & \\
$\mathrm{~B}(\mathrm{n}=4)$ & $71.4 \pm 0.6$ & $27.4 \pm 0.4$ & $<0.5$ & $<0.5$ \\
& & & & $<0.5$ \\
$\mathrm{C}(\mathrm{n}=4)$ & $71.7 \pm 0.5$ & $27.5 \pm 0.4$ & $<0.5$ & \\
\hline
\end{tabular}

Samples taken on another occasion confirmed a methane content just over $70 \%(\mathrm{v} / \mathrm{v})$ when the two-step process was working properly. Biogas from a one-step manure-based plant (Laholm, Sweden) was found to contain about 5\% less methane. The complex microbiology of anaerobic digestion of organic wastes [5] is expected to result in different proportions of methane and carbon dioxide depending on the proportions of intermediate substrates. 
Table 2. Volatile $\mathrm{C}_{6}-\mathrm{C}_{11}$ hydrocarbons in biogas from household solid waste (gas sample taken 26 November 1996; total concentration $550 \mathrm{mg} \mathrm{m}^{-3}$ ).

\section{Concentration $\left(1 \mathrm{~atm}, 20^{\circ} \mathrm{C}\right)$}

Hydrocarbon

$\left(\mathrm{mg} \mathrm{m}^{-3}\right)$

(ppmv)

$\begin{array}{lcc}\text { Benzene } & 0.05 & 0.01 \\ \text { Toluene } & 1 & 0.2 \\ \alpha \text {-Pinene } & 4 & 0.7 \\ \text { B-Pinene } & 3 & 0.5 \\ p \text {-Cymene } & 400 & 70 \\ \text { Limonene } & 90 & 20 \\ \text { Undecane } & 3 & 0.5\end{array}$

Non-methane hydrocarbons

The results given in Table 2 reflect the content in biogas from household solid waste of hydrocarbons in the range suited to adsorption sampling on the Tenax polymer. It is seen that p-cymene (4-methylisopropylbenzene) was the major polluting hydrocarbon constituting $0.4 \mathrm{~g} \mathrm{~m}^{-3}$ or $0.007 \%(\mathrm{v} / \mathrm{v})$ of the total biogas. The second most prominent compound was limonene (4-isopropenyl-1-methylcyclohexene). The chromatogram in Figure $3 \mathrm{~b}$ illustrates the separation of these hydrocarbons as well as the presence of several other minor compounds including several monoterpenes. The time scale includes the initial thermal desorption period. The hydrocarbons reported in Table 2 and several additional trace components were unequivocally identified by their mass spectra on parallel analysis by GS-MS. Samples taken on other occasions were found to contain the reported compounds in similar proportions. 

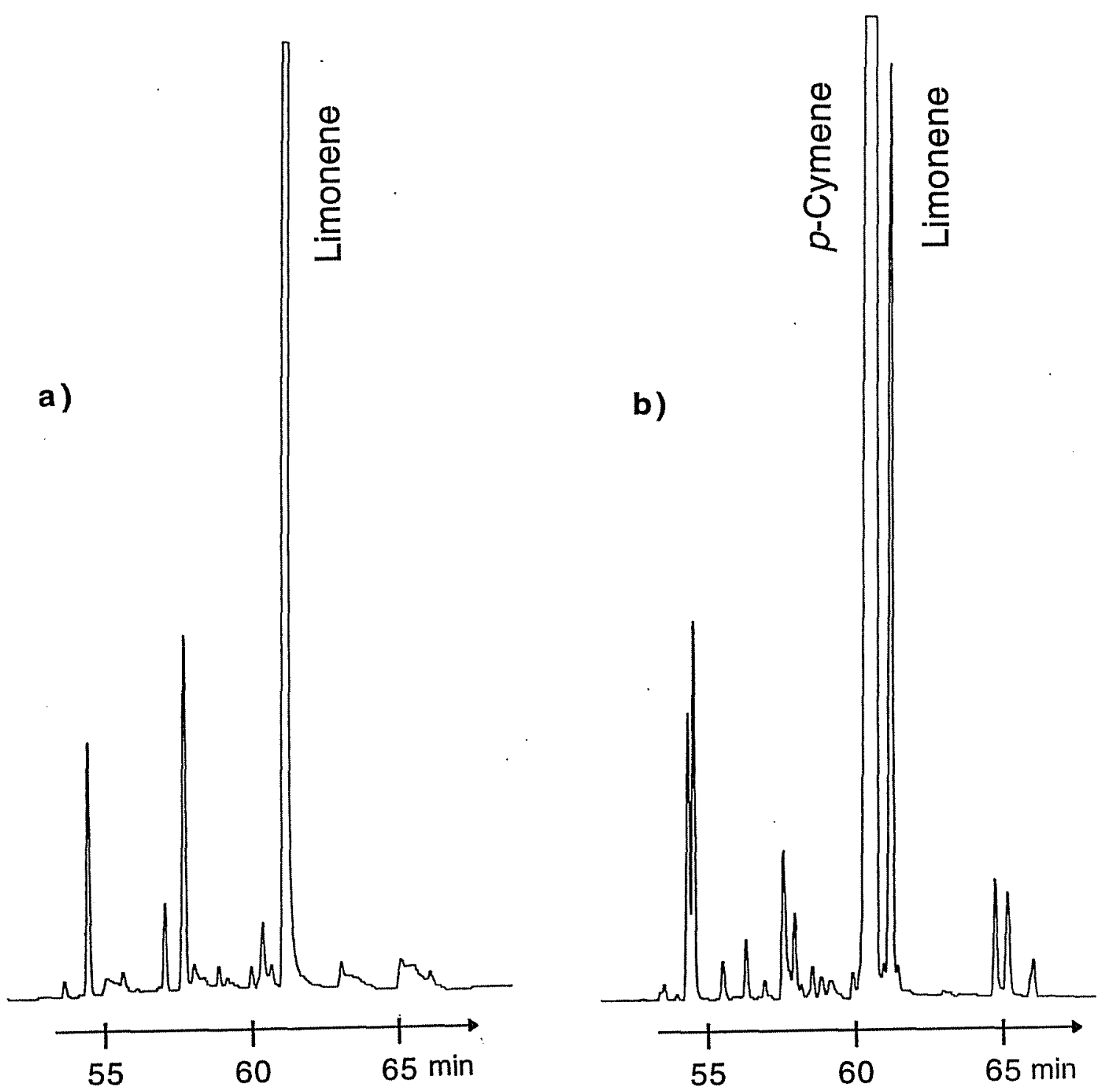

Figure 3 Gas chromatographic assessment (methylsilicone capillary column) of $p$-cymene and monoterpenes from the biogas production process. a) Air in the drum sieve b) Biogas produced from household solid waste. 
The presence of $p$-cymene as the most prominent hydrocarbon may be explained by rearrangement and dehydrogenation of limonene and other monoterpenes at the low $\mathrm{pH}$ in the hydrolysis step. Conversion of monoterpenes to $p$-cymene is known from the acidic sulphite pulping process [6,7]. Samples taken above the organic waste in the drum sieve demonstrated a high content of limonene and a low content of $p$-cymene before the hydrolysis step (Figure $3 \mathrm{a}$ ). In samples of the hydrolysis gas, the amount of $p$-cymene tended to be larger than that of limonene. The origin of limonene and other monoterpenes is likely to be household solid waste components such as citrus fruit peels, which are very rich in these hydrocarbons. The presence of $p$-cymene and monoterpenes in biogas is consistent with observations that anaerobic microorganisms are less efficient in metabolising certain types of compounds $[5,8]$.

Among other non-methane hydrocarbons of specific interest, benzene and toluene (methylbenzene) are eluted before the monoterpenes and were determined by GC-MS in trace amounts. Food waste may contain air-contaminating hydrocarbons since the lipophilic hydrocarbons are easily absorbed from air by fat. Benzene occurs in petrol and probably originates mainly from petrol-fuelled vehicles. The concentration in the biogas of this carcinogenic hydrocarbon was not higher than the normal level inside vehicles in urban traffic [9]. Toluene often occurs in solvents. The last hydrocarbon reported in Table 2, undecane, is characteristic of diesel oil and emissions from diesel vehicles.

\section{CONCLUSIONS}

The high content of methane, exceeding $70 \%(\mathrm{v} / \mathrm{v})$ from the two-step plant investigated, adds to other arguments for using biogas from source-separated household solid waste as an energy source. The content of methane, carbon dioxide, nitrogen and oxygen can be rapidly and accurately checked by gas chromatographic methods. Adsorbent sampling followed by gas chromatographic analysis can be favourably used for monitoring minor hydrocarbons in biogas. Although hydrocarbons should be harmless when biogas is used as a fuel, the unexpectedly high content of $p$-cymene demonstrates the need for analysing potentially harmful minor components. 


\section{ACKNOWLEDGEMENTS}

Sampling assistance and generous information was obtained from Johan Wallin at the Sobacken biogas plant in Borås.

\section{REFERENCES}

1. Mata-Alvarez J., Biological household waste treatment in Europe: second Aalborg international conference. Resources, Conservation and Recycling, 17, 67-73 (1996).

2. Biogas from municipal solid waste. Overview of systems and markets for anaerobic digestion of MSW. IEA Bioenergy Agreement, Task XI: Conversion of MSW feedstock to energy. Activity 4: Anaerobic digestion of MSW, 1994. (1994).

3. Rijkens B.A. and Voetberg J.W., Two-step anaerobic digestion of solid wastes. In: Anaerobic digestion and carbohydrate hydrolysis of waste, Ferrero G., Ferrati M. and Naveau H. (eds.), Elsevier Applied Science Publishers, London, pp 479-481 (1984).

4. Ghosh S., Ombregt J.P. and Pipyn P., Methane production from industrial wastes by two-phase anaerobic digestion. Water res., 19, 1083 - 1088 (1985).

5. Zinder S. H., Microbiology of anaerobic conversion of organic wastes to methane: Recent developments, ASM News, 50, 294-298 (1984).

6. Strömvall A-M. and Petersson G., Terpenes emitted to air from TMP and sulphite pulp mills. Holzforschung, 46, 99-102 (1992).

7. Sjöström E., Wood chemistry - Fundamentals and Applications, Second edition, Academic Press Inc., San Diego, pp 135-136 (1993). 
8. Speece R. E., Anaerobic biotechnology for industrial waste water treatment. Environ. Sci. Technol., 17, 416-427 (1983).

9. Barrefors G. and Petersson G., Exposure to volatile hydrocarbons in commuter trains and diesel buses. Environ. Technol., 17, 643-647 (1996). 